\title{
EDITORIAL
}

\section{MORIR EN ARICA: UNIVERSALIDAD Y PARTICULARIDAD DE LA RITUALIDAD EN LOS ANDES CENTRO-SUR}

\author{
DAYING IN ARICA: UNIVERSALITY AND PARTICULARITY OF \\ ITS RITUALITY IN THE SOUTH CENTRAL ANDES
}

\author{
Thérèse Bouysse-Cassagne ${ }^{1}$
}

Dos ideas principales marcaron la concepción y las evoluciones de los proyectos ECOS C06H04 y PICS 4796 que dieron origen a los manuscritos que forman parte de este número de Chungara. En primera instancia hemos pensado que la temática de la muerte sería la más adecuada para facilitar el intercambio entre arqueólogos e historiadores participantes de dicho proyecto, al mismo tiempo que permitiría la inscripción de nuestro trabajo dentro de una larga perspectiva temporal. En efecto, nuestro punto de partida surgió de la idea conocida de Philippe Ariès a saber que:

los cambios del hombre ante la muerte, o son muy lentos, o se sitúan entre largos periodos de inmovilismo (...) por este motivo el observador que quiere llegar a un conocimiento que escapa a los contemporáneos debe ampliar su campo de visión y extenderlo a un periodo de duración más largo que el que separa a dos grandes etapas de cambios sucesivos. Por este motivo el historiador de la muerte no debe temer abarcar siglos o incluso milenios, puesto que los errores que no puede dejar de cometer son menos graves que los anacronismos de comprensión a los que se expone una cronología demasiado corta (Ariès 1975:12).

El uso de una perspectiva temporal de larga duración no significó, obviamente en este caso, desarrollar un relato unilineal acerca de la historia de la muerte a través de los siglos, sino tomar en cuenta la existencia de periodos de larga duración y periodos de ruptura que se debían identificar; por lo que la sucesión de artículos seleccionados para el presente número deben ser leídos desde esa perspectiva. Por otro lado, la segunda idea que motivó la escritura de los estudios consistió en desenclavar un conocimiento científico que, hoy todavía, tomando en cuenta las políticas patrimoniales de los distintos estados -Perú, Bolivia, Chile- se funda a menudo en las divisiones territoriales republicanas, en vez de contemplar para el periodo prehispánico las diferencias geoecológicas y los intercambios de varias índoles que existieron entre las poblaciones de las tierras altas de los dos primeros países y los valles intermedios y la costa del Pacífico en el sur de Perú y norte de Chile. Para los Andes, la idea de la importancia de los diferentes pisos ecológicos y su complementariedad han sido contemplados desde el punto de vista económico esencialmente, por lo que situar las prácticas rituales en el marco de la variabilidad ecológica altitudinal permitió pensar también en complementariedades rituales como las que fueron estudiadas por Duviols para los Huari y Llacuaz del Perú central (Duviols 1974).

Por otro lado, demostrar la singularidad de una cultura como la de los Chinchorro (7.000-4.500 a.p.) estudiada por Santoro et al. (2012) ligada a un solo medio ambiente -el de las riquezas marítimas- permite entender hasta qué punto esta dependió de los episodios climáticos ligados a la ocurrencia o no de la corriente de Humboldt. Aunque los Chinchorro se hayan establecido en las costas del norte chileno, y las poblaciones del valle de Azapa (estudiadas por Muñoz 2012) se asentaran en tierras situadas cerca de fuentes de agua, durante el Formativo, no podemos limitarnos a considerar que las ocupaciones de los lugares donde se instalaron ambas culturas respondían tan sólo a criterios utilitarios ligados al ecosistema. Obviamente, los beneficios que se pidieron a la naturaleza variaron según los distintos modos de vida de las poblaciones, pero antes de que el medio ambiente impusiera su ley a las primeras ocupaciones humanas, existieron actitudes

Directrice de recherches émérite au CNRS, Paris, France. therese.bouysse.cassagne@gmail.com 
religiosas que pusieron sus límites restrictivos al poblamiento o que organizaron las orientaciones de las viviendas o de las tumbas.

Efectivamente, uno se sorprende pensando que las zonas de montaña dieron lugar a una gran diversidad de tipos de poblamiento. Algunas regiones montañosas como las de Kabylie, en Argelia, están densamente pobladas, mientras que las de Japón están abandonadas y cubiertas de selva. Estas oposiciones no derivan necesariamente de factores climáticos. Por ejemplo, constatamos que en América del Sur a una misma latitud, las zonas altiplánicas de Bolivia y Perú fueron relativamente bien pobladas, mientras que las altiplanicies y cadenas montañosas de la costa brasileña fueron poco habitadas desde la prehistoria hasta la actualidad.

Por otro lado, a partir del periodo Intermedio Tardío (ca. 1.000-1.350 d.C.) sabemos que las tumbas de los valles occidentales y del altiplano fueron orientadas hacia el este así como las viviendas. Esta analogía espacial existió en Europa entre los Burgondes y los Francos, por ejemplo, que también adoraban al Sol. Pero en los Andes no sólo las orientaciones solares influyeron en la construcción de los monumentos, sino que los altos montes y los glaciales (Duffait 2012) dictaron también la implantación de apachetas y punkus a lo largo de las rutas.

En el análisis de esta geografía del poblamiento a través de las construcciones funerarias de la región de Arica y del culto a los muertos, constatamos que ninguna de las culturas contempladas hizo desaparecer a sus muertos, como ocurre en otras regiones del mundo. Los Koriak de la costa del Pacífico en Siberia botaron los cuerpos de sus muertos al mar; los Massai del noreste de África central los entregan a las hienas y los Bantu botan los cuerpos de las mujeres al río, mientras que grupos del Sudán nilótico, los Somalí, los Bosquimanos y los de la Costa de Marfil también abandonan los cuerpos de sus difuntos. Al contrario de aquellas culturas, el sumo cuidado prodigado a los cadáveres y el desarrollo de técnicas de conservación constituyen un rasgo general compartido por todas las culturas estudiadas de la región desde 10.000 a.p.

Aunque los grupos de pescadores recolectores de la costa chilena no construyeron edificios donde colocar sus muertos, inventaron técnicas complejas para el tratamiento y conservación de ciertas partes de los cuerpos, conocidas hoy día como las más antiguas del mundo. Los procedimientos se aplicaron a un amplio espectro de la población, niños y fetos incluidos, contrariamente al antiguo Egipto donde el culto a los cuerpos momificados se orientó, en primer lugar, a los soberanos de las dinastías gobernantes, llegando a su cúspide en torno al año 2.000 a.p. Aunque hubo diferenciaciones internas entre los Chinchorro, pocos fueron los que no se momificaron. Además, los muertos chinchorro fueron agrupados en conjuntos de varios individuos de diferentes edades y sexo, cubiertos por una misma estera, pero ignoramos si estas agrupaciones eran parte de linajes o de grupos significativos de otra índole.

Con las sociedades de agricultores andinos, o neolíticas, la conservación y tratamiento de los muertos prosiguió, pero sin intervenir los cuerpos como los Chinchorro. Los esfuerzos se volcaron en cambio a las construcciones de obras arquitectónicas funerarias que alteraron las geoformas del paisaje. Así desde el Formativo hasta épocas tardías se levantaron sucesivamente túmulos, grutas funerarias, cistas, tumbas familiares (chullpas), comportamiento que permitió otorgar a los muertos una de las marcas más visibles de la vida, una habitación sólida, permanente. En todos los casos, las tumbas solitarias constituyeron una excepción.

En cuanto a las chullpas, el número de los parientes enterrados con el antepasado atestiguaba del poder de este último sobre su ayllu. Como lo demostró Louis Vincent Thomas para las sociedades africanas, "es en función de la integración social del muerto y del papel que pudo desempeñar durante su vida que se movilizan o no un gran número de parientes" (Thomas 1988). Según esta lógica, que también se verifica en los Andes, el tamaño de la tumba y los ritos funerarios constituyen uno de los indicadores más pertinentes para medir la importancia social del ayllu y el peso político del difunto.

Estos ritos deben ser interpretados además como deseos de buen suceso para la inserción social del nuevo difunto en el seno de la comunidad de los ancestros. Las chullpas fueron tan importantes para los ayllu, organización de linajes fundada en lazos de sangre y de territorialidad que en algunas regiones -como los Pacaj-siguieron construyéndolas hasta el siglo XVI. Estos monumentos funerarios no tuvieron la misma arquitectura en todas las regiones, como Duchesne y Chacama (2012) lo demuestran, pero este sistema de tumba colectiva fue muy difícil de hacer desaparecer durante la Colonia. Entre los sistemas religiosos que tuvieron más influencia sobre las formas de organización social y territorial 
figuran sin lugar a dudas las sociedades clánicas y totémicas, que reúnen a individuos que consideran que descienden de un ancestro común, y el ayllu entra en esta categoría. En este caso, otro de los elementos más característicos de esta formación social es efectivamente la identificación de un mismo territorio para todos los descendientes del grupo. Con el ayllu, la sacralización del espacio obedeció, como lo demuestra el estudio de Bouysse-Cassagne y Chacama (2012), a complejas reglas de jerarquización del culto a los muertos relacionadas con la tenencia colectiva de la tierra y la sacralización del espacio. Mientras para las tribus inuit de la Bahía de Hudson la tumba facilitaba la ubicación en el espacio del alma vagabunda, en los Andes Centro-sur el túmulo o la chullpa, visible desde lejos y que albergaban los cuerpos de los difuntos garantes de la fuerza animadora y fecundante (camay), constituyeron verdaderos santuarios cargados de fuerza para los vivos y "lugares de memoria" para la parentela.

En los Andes, uno de los más extraordinarios ejemplos de voluntad de transformación del poblamiento y del culto a los muertos lo constituyen los pueblos de reducción fundados por los españoles según las normas dictadas por los concilios de Lima de 1567 y 1583 . Con los cementerios, los muertos, que hasta entonces se encontraban alejados de los pueblos, y cuyo culto estaba vinculado con los montes y la tierra, debían entrar en los poblados. Este proceso dio lugar a múltiples y complejas adaptaciones que se analizan en este número de la Revista. El tipo de segregación ideológica introducida por los cementerios cristianos debió producirse en varios momentos de la historia y es muy probable que varios pueblos europeos nacieran también como poblados de misión durante los grandes empujes misionales de los siglos VI y XI.

El suceso de las reducciones como el de los cementerios cristianos varió según las regiones, como lo demuestra Gabriela Ramos (2010) para los indios del Cuzco y de Lima, que se hicieron enterrar en las iglesias, contribuyendo de esta forma a la integración de las élites indígenas urbanas en el seno de la nueva sociedad de los dos primeros siglos de la Colonia. Sin embargo, tal no parece haber sido el caso en la región de Arica con sus pueblos aislados, poco y mal evangelizados (Marsilli y Cisternas 2010). Comparando la realidad andina con la mexicana Pierre Ragon (2012) defiende la idea de que en México la falta de interés por los rituales indígenas de la muerte no significa que en ese lugar la cristianización resultó más fácil que en los Andes, sino que los rituales indígenas, más discretos, resultaron desapercibidos durante muchos años por parte de los religiosos.

\section{Referencias Citadas}

Ariès, P. 1975. Essais sur la mort en Occident du Moyen-Age à nos Jours. Le Seuil ed, Paris.

Bouysse-Cassagne, T. y J. Chacama 2012. Partición colonial del territorio, cultos funerarios y memoria ancestral en Carangas y precordillera de Arica (siglos XVI-XVII). Chungara Revista de Antropología Chilena 44:669-689.

Duchesne, F. y J. Chacama 2012. Torres funerarias prehispánicas de los Andes del Centro Sur: muerte, ocupación del espacio y organización social. Estudio comparativo: Coporaque, Cañón del Colca (Perú), Chapiquiña, precordillera de Arica (Chile).Chungara Revista de Antropología Chilena 44:605-619.

Duffait, E. 2012. Vías prehispánicas y culto de los muertos en el norte chileno (Arica-Tarapacá) durante el período Intermedio Tardío y el Horizonte Tardío (ca. 1.000-1.532 d.C.). Chungara Revista de Antropología Chilena 44:621-635.

Duviols, P. 1973. Huari y Llacuaz. Agricultores y pastores. Un dualismo prehispánico de oposición y complementariedad. Revista del Museo Nacional de Lima 29:153-191.
Marsilli, M.N. y P. Cisternas 2010. Los senderos de la idolatría: el viaje de Vázquez de Espinosa por los altos de Arica, 1618. Chungara Revista de Antropología Chilena 42:465-476.

Muñoz, I. 2012. Agua y monumentalidad en el valle de Azapa: indicadores del uso del espacio en las poblaciones del Alto Ramírez, periodo Formativo, norte de Chile. Chungara Revista de Antropología Chilena 44:571-591.

Ragon, P. 2012. La muerte cristiana entre la pastoral evangelizadora y las prácticas indígenas: un acercamiento comparatista (México Central y los Andes del Centro-Sur, siglo XVI- Principio del XVII). Chungara Revista de Antropología Chilena 44:691-705.

Ramos, G. 2010. Muerte y Conversión en los Andes, Lima y Cuzco, 1532-1670. IEP-IFEA, Lima.

Santoro, C.M., M.M. Rivadeneira, C. Latorre, F. Rothhammer y V.G. Standen 2012. Rise and decline of the Chinchorro marine hunter-gatherer landscape in the hyper arid coast of the Atacama Desert. Chungara Revista de Antropología Chilena 44:637-653.

Thomas, L.V. 1988. Anthropologie de la Mort. Payot, Paris. 
